\title{
Gastric Cancer pT4 TNM Finding v8
}

National Cancer Institute

\section{Source}

National Cancer Institute. Gastric Cancer pT 4 TNM Finding v8. NCI Thesaurus. Code C133614.

Gastric cancer with tumor invading the serosa (visceral peritoneum) or adjacent structures. The adjacent structures of the stomach include the spleen, transverse colon, liver, diaphragm, pancreas, abdominal wall, adrenal gland, kidney, small intestine, and retroperitoneum. Intramural extension to the duodenum or esophagus is not considered invasion of an adjacent structure, but is classified using the depth of the greatest invasion in any of these sites. (from AJCC 8th Ed.) 